\title{
Direito À MORAdia E JUdicializaÇÃo: atuação da Defensoria Pública Paulista
}

\author{
Eliane Alves da SILVA* \\ Francisco de Assis COMARU* \\ Sidney Jard da SILVA**
}

\begin{abstract}
RESUMO: Este artigo propõe discutir a atuação da Defensoria Pública do Estado de São Paulo (DPESP) nos conflitos fundiários urbanos, com base na questão do papel que a instituição vem desempenhando no cumprimento do direito social à moradia. Para isso toma por objeto central os discursos dos profissionais atuantes na instituição, com foco nas ações realizadas pelo Núcleo Especializado de Habitação e Urbanismo (NHU), apreendidas por meio de entrevistas e levantamento documental. O texto se orienta pelo referencial teórico da judicialização das políticas sociais, apontando para os dilemas e limites da judicialização no campo da moradia. Conclui que o trabalho da Defensoria Paulista tem sido, sobretudo, o de afirmar o direito à moradia como direito social a ser promovido pelo Estado, o que se dá pela afirmação da relação intrínseca entre esse direito e o cumprimento da função social da propriedade, além dos direitos relacionados à posse.
\end{abstract}

PALAVRAS-CHAVE: Defensoria Pública. Conflitos fundiários urbanos. Direito à moradia. Função social da propriedade. Judicialização.

\footnotetext{
UFABC - Universidade Federal do ABC. Programa de Pós-Graduação em Ciências e Humanidades (PCHS). São Bernardo do Campo - SP - Brasil. 09606-070 - eliane.alves@ufabc.edu.br. https://orcid.org/ 0000-0001-6925-8665

* UFABC - Universidade Federal do ABC. Programa de Pós-Graduação em Planejamento e Gestão do Território (PGT). Santo André - SP - Brasil. 09210-580 - francisco.comaru@ufabc.edu.br. http://orcid.org/ 0000-0002-1091-2156.

*** UFABC - Universidade Federal do ABC. Programa de Pós-Graduação em Ciências e Humanidades (PCHS). São Bernardo do Campo - SP - Brasil. 09606-070 - sidney.jard@ufabc.edu.br. https://orcid.org/ 0000-0003-3444-1763.
} 


\section{Introdução}

Hoje, me parece que o grande problema, acho que ninguém conseguiu responder com razoabilidade, e é difícil mesmo, é o que quer dizer esse direito à moradia do artigo sexto da Constituição (Defensora Pública) ${ }^{1}$.

O direito à moradia foi incorporado à Constituição Federal (BRASIL, 2017) como direito social fundamental somente no ano de 2000, por meio da Emenda Constitucional $\mathrm{n}^{\circ} 26$. Um ano mais tarde foi reafirmado no Estatuto da Cidade pela Lei 10.257 de 2001 (BRASIL, 2002), lei federal que regulamentou os artigos constitucionais referentes à política urbana. Mas a despeito de seu reconhecimento formal, esse direito ainda carece de real efetivação no Brasil. Por um lado, a oferta pública de habitação popular, representada atualmente sobretudo pelo programa federal Minha Casa Minha Vida (PMCMV), tem sido objeto de restrições e incertezas quanto às modalidades de sua continuidade (CARDOSO; ARAGÃO; JAENISCH, 2017). Por outro, o acesso privado à terra urbana e à moradia por parte da população de baixa renda, dentro dos padrões da urbanização brasileira, é fortemente marcado pela precariedade urbanística e a irregularidade jurídica, levando não só a condições precárias de vida na cidade mas também a situações de insegurança na posse (ROLNIK, 2015), que não raro se desdobram em conflitos fundiários urbanos, cuja expressão mais extrema são as remoções forçadas.

Para fins de tratamento político do tema, o Brasil trabalha com uma definição formal dos conflitos fundiários, proposta pela Resolução no. 87 de 2009, do Conselho das Cidades, que define tais conflitos como

disputa[s] pela posse ou propriedade de imóvel urbano, bem como impacto de empreendimentos públicos e privados, envolvendo famílias de baixa renda ou grupos sociais vulneráveis que necessitem ou demandem a proteção do Estado na garantia do direito humano à moradia e à cidade (BRASIL, 2010).

Com maior ou menor visibilidade, tais conflitos fazem parte do cotidiano das cidades brasileiras, cujos desdobramentos, por vezes violentos e arbitrários, produzem violação de direitos, em clara afronta às normas legais nacionais, e mesmo internacionais, em relação ao cumprimento do direito à moradia e aos direitos humanos (SILVA; TEIXEIRA, 2016). Somente no ano de 2017, na Região Metropolitana de São Paulo (RMSP) foram removidas mais de 5.500 famílias, sendo que mais de 20.000 mil estavam sob ameaça de remoção nesse mesmo ano².

\footnotetext{
Entrevista concedida à autora em 21/06/2017.

2 Segundo Observatório de Remoções. Dados disponíveis em: https://www.observatorioderemocoes. fau.usp.br. Acesso em 20 de abril de 2018.
} 


\section{Direito à moradia e judicialização: atuação da Defensoria Pública Paulista}

Tais números devem ser lidos em um contexto mais amplo de déficit habitacional popular nas cidades brasileiras, dentro do qual as ocupações urbanas aparecem como uma alternativa de moradia, ainda que precária. Segundo dados da Fundação João Pinheiro (FJP, 2018), eram estimados 7,906 milhões de imóveis vazios no país, em 2015. O número supera o déficit habitacional estimado para o mesmo ano, de 6,355 milhões de domicílios (FJP, 2018). Assim, pode-se concluir que ao menos parte do déficit habitacional poderia ser suprido se fossem efetivados mecanismos de cumprimento da função social da propriedade, o que coloca esse preceito constitucional no centro dos conflitos fundiários urbanos ${ }^{3}$.

A legislação brasileira reconhece formas irregulares de ocupação do solo urbano caracterizadas pela posse não titulada. Assim, o Estatuto da Cidade prevê instrumentos variados para o reconhecimento legal dessas ocupações, tais como a regularização fundiária, as zonas especiais de interesse social (ZEIS) e a usucapião especial de imóvel urbano, para imóveis privados. Para imóveis públicos a Lei $11.481 / 2007$ prevê a concessão de uso especial para fins de moradia (CUEM) ${ }^{4}$. Todos estes instrumentos são voltados para inserir as ocupações irregulares no quadro formal das cidades, possibilitando-lhes regularização e segurança jurídica.

Ainda no que se refere à questão fundiária no país, a Constituição Federal de 1988 (BRASIL, 2017) afirmou o direito de propriedade entre os direitos individuais fundamentais ( $\operatorname{art} .5^{\circ}$ ), condicionando seu exercício ao cumprimento de sua função social (art. $5^{\circ}$., XXII e XXIII), que afirma que a propriedade deve ser balizada pelo bem coletivo, conforme definição apresentada mais tarde no Estatuto da Cidade (cap. III, art. 39):

A propriedade urbana cumpre sua função social quando atende às exigências fundamentais de ordenação da cidade expressas no Plano Diretor, assegurando o atendimento das necessidades dos cidadãos quanto à qualidade de vida, à justiça social e ao desenvolvimento das atividades econômicas, respeitadas as diretrizes previstas no art. $2^{\circ}$. desta lei (BRASIL, 2002).

A positivação constitucional de tais direitos é acompanhada de dois efeitos: por um lado, evidencia-se o conflito entre posse e propriedade titulada, levando à colidência entre o direito social à moradia e o direito de propriedade, expressa, por exemplo, em condições em que populações vulneráveis ocupam irregularmente

\footnotetext{
3 A Fundação João Pinheiro aponta para a necessidade de melhor caracterizar os imóveis vagos, "tanto para o delineamento do perfil desses domicílios quanto para a identificação da parcela que mais provavelmente poderia ser direcionada a suprir parte das carências de habitação da população". (FJP, 2018, p. 37).

4 A CUEM foi inicialmente vetada no Estatuto da Cidade, sendo reapresentada por meio da Medida Provisória no. 2.220/2001, até ser reconhecida pelo Código Civil por meio da Lei 11.481/2007.
} 
propriedades que não cumprem sua função social e reivindicam seu direito de nela permanecer e adquirir-lhe o domínio.

Por outro, apresenta-se a obrigatoriedade do Estado em fazer cumprir os direitos constitucionalmente estabelecidos, sendo que sua não garantia pode levar a processos de judicialização da política, isto é, ao acionamento do sistema de justiça a fim de garantir o cumprimento dos direitos positivados.

A defesa de que existem direitos decorrentes da posse e a cobrança de que a propriedade cumpra sua função social estão entre os principais argumentos apresentados pela defesa jurídica de moradores em condições de irregularidade, quando da reivindicação pelo seu direito à moradia. Tem-se aí uma dupla chave problemática, em termos do entendimento jurídico dos direitos de propriedade e de moradia. Por um lado, o caráter supostamente intocável do direito de propriedade, que sofreria limitações indevidas pela exigência de cumprimento da função social. Os efeitos disso são a sistemática desconsideração da função social nas decisões judiciais envolvendo os conflitos fundiários. Nesse sentido, parte da literatura aponta para o que seria o formalismo do Judiciário (SAULE Jr.; DI SARNO, 2013), com decisões orientadas sobremaneira pela defesa da propriedade individual titulada, a despeito de não cumprir sua função social (LOPES, 2014; AVANCI, 2014; VELOSO; PEIXOTO; FABER, 2017; MILANO, 2017).

Adicionalmente, tem-se o próprio direito à moradia que com conteúdo pouco adensado na sua enunciação constitucional abre a discussão sobre a forma como deve ser entendido e as obrigações estatais que dele decorrem. A enunciação do direito à moradia no texto constitucional, por seu caráter largo e abrangente, teria deixado à interpretação dos operadores do Direito o conteúdo de sua efetivação, deixando em aberto questões como a "natureza desse direito; seu conteúdo mínimo; quais as prestações devidas pelo Estado; quem são seus titulares; de que ente estatal ele deve ser exigido; se oponível aos particulares" (NASSAR, 2011, p. 42).

Desse modo, o próprio conteúdo do direito à moradia se transforma em objeto de disputa, não só no campo jurídico, como nos campos social e político, onde se briga em torno da afirmação e da efetivação desse conteúdo, uma vez que o texto constitucional permite interpretações distintas, levando à questão posta por Souza Neto (2010, p. 518), quando este trata da justiciabilidade dos direitos sociais e aponta para o fato de que "o problema não é apenas de interpretação do direito, mas de decisão política. É necessário decidir qual das interpretações normativamente autorizadas deve prevalecer”. É nesse campo de disputa que se localiza a atuação da Defensoria Pública, uma vez que nos conflitos fundiários as pessoas de baixa renda podem recorrer à instituição para sua defesa jurídica 5 .

\footnotetext{
5 A partir de 2015, com a edição do Novo Código de Processo Civil (NCPC), a presença da Defensoria torna-se obrigatória em casos de conflitos que envolvam populações em situação de hipossuficiência econômica.
} 


\section{Direito à moradia e judicialização: atuação da Defensoria Pública Paulista}

Assim, pensando no contexto paulista, diante do quadro no qual se insere o direito à moradia (pouco reconhecido) e a dimensão dos conflitos fundiários urbanos, cumpre indagar sobre que papel a Defensoria Pública do Estado de São Paulo (DPESP) desempenha na efetivação do direito à moradia adequada, questão central desse artigo. Por meio da investigação sobre as percepções dos próprios atores institucionais, pergunta-se, em que medida a atuação da Defensoria Paulista tem sido capaz de tensionar o dito formalismo do Judiciário, em termos dos conflitos entre direitos sociais (direito à moradia) e direito privado (primazia da propriedade individual titulada) e de fazer avançar o reconhecimento do direito à moradia, pondo em perspectiva os alcances da própria judicialização.

Propõe-se responder a tais questões com base na análise dos discursos e percepções dos próprios operadores, e na perspectiva dos agentes vinculados à Defensoria Paulista. Nesse sentido é que a pesquisa cobriu um leque variado de atores no interior da instituição, buscando apreender diversidades de ações, com o objetivo de ampliar, o máximo possível, o campo de avaliações sobre as questões em pauta. $\mathrm{O}$ foco principal da pesquisa foi a atuação do Núcleo Especializado de Habitação e Urbanismo (NHU), dedicado ao tratamento coletivo das demandas nesses temas. Adicionalmente, foram realizadas entrevistas na Ouvidoria da Defensoria Paulista, órgão responsável pela interface entre a instituição e a sociedade civil; no Centro de Atendimento Multidisciplinar (CAM) da unidade central do município de São Paulo-SP, dedicado ao tratamento interdisciplinar das demandas; em unidades locais da Defensoria nos municípios de Osasco-SP e Mogi das Cruzes-SP ${ }^{6}$. Em menor número, foram realizadas entrevistas com agentes de órgãos externos, com quem a DPESP mantém convênios para a defesa jurídica da população de baixa renda, entre eles o Escritório Modelo D. Paulo Evaristo Arns (PUC/SP) e o Centro Gaspar Garcia de Direitos Humanos.

A pesquisa realizou-se por meio de entrevistas, com roteiros semiestruturados, visando obter o discurso dos atores como objeto central da análise. De forma complementar, contou ainda com levantamento de material institucional, como boletins periódicos, regulamentos, e demais documentos formais, disponíveis na página da instituição na internet. As entrevistas foram realizadas no período de julho de 2016 a novembro de $2017^{7}$.

Afim de responder as questões propostas o presente artigo se divide em duas seções, além da introdução e da conclusão. Na primeira situa-se a relação entre Defensoria Paulista e a defesa do direito à moradia, por meio de seu Núcleo Especializado de Habitação e Urbanismo (NHU). A segunda investiga o tema da

\footnotetext{
6 A escolha desses municípios se deu pelo interesse em pautas específicas nas quais os defensores de referência estavam ligados e se mostraram de interesse da pesquisa.

7 A pesquisa contou com financiamento da Coordenação de Aperfeiçoamento de Pessoal de Nível Superior (CAPES).
} 
judicialização do direito social à moradia, buscando problematizar seus alcances e seus limites.

\section{Defensoria Paulista e direito à moradia: o Núcleo Especializado de Habitação e Urbanismo (NHU)}

As defensorias públicas foram previstas na Constituição Federal de 1988 (BRASIL, 2017), como parte das funções essenciais à justiça, cabendo-lhes a prestação de assistência jurídica, e a defesa, judicial e extrajudicial, dos direitos individuais e coletivos, de forma integral e gratuita, aos cidadãos que comprovarem insuficiência de recursos ${ }^{8}$.

O ritmo de instalação das defensorias públicas no país foi bastante desigual e o estado de São Paulo a instituiu tardiamente, apenas em $2006^{9}$, tendo exigido, para isso, ampla mobilização de grupos da sociedade civil organizada e de movimentos sociais. Além desse aspecto, a criação de uma ouvidoria externa e a participação popular por meio de conferências, ajudam a fazer desta instituição um caso tido como inovador no quadro das defensorias do país (MUNIZ, 2011; CARDOSO, $2010)^{10}$.

A lei de criação da DPESP previu, na sua estrutura, a existência dos chamados Núcleos Especializados, cujas atribuições têm enfoque (ainda que não exclusivo) na dimensão coletiva dos direitos, seja por meio da tutela coletiva na representação nos litígios, seja porque entre suas atribuições prevê-se realizar e estimular o diálogo com a gestão pública, competindo-lhes a fiscalização e a interlocução no desenho e efetivação das políticas públicas ${ }^{11}$. Entres estes núcleos está o Núcleo de Habitação e Urbanismo (NHU), criado em 2007, profundamente ligado com as demandas dos movimentos de moradia (MUNIZ, 2011).

Por seu papel de atuação estratégica, voltada à defesa dos direitos coletivos, seja via judicialização, seja na interlocução com a gestão pública, a observação do

\footnotetext{
8 "Art. 134, Seção IV, "Da Defensoria Pública". A redação atual do artigo foi dada pela Emenda Constitucional no. 80, de 2014. (BRASIL, 2017)

9 Por meio da Lei Complementar no. 988/2006.

${ }^{10}$ Mais recentemente, no entanto, a polêmica alteração na forma de eleição do ouvidor geral da DPESP, que deixou de ser feita pela sociedade civil organizada passando ao controle da própria Defensoria, levanta questões sobre a burocratização da instituição e o distanciamento em relação a seus princípios fundadores. Do mesmo modo, o poder do Conselho Superior da Defensoria Pública, órgão frequentemente apontado (por atores internos ou externos à instituição) pelo seu distanciamento em relação à sociedade civil, faz refletir sobre o alcance e permanência das promessas iniciais. $\mathrm{O}$ tema, no entanto, ultrapassa os objetivos desse artigo.

11 Lei Complementar Estadual no. 988/2006, art. 53, II e IV. Disponível em: https://www.al.sp.gov.br/ repositorio/legislacao/lei.complementar/2006/lei.complementar-988-09.01.2006.html. Acesso em: 20 de março de 2018.
} 
NHU permite entender, de forma mais ampla, o papel que se espera que a Defensoria Pública desempenhe na proteção e promoção do direito à moradia, ao abordar a questão do ponto de vista coletivo e, portanto, em diálogo com os direitos sociais.

A partir da análise dos discursos e ações institucionais, defendemos que o principal papel da Defensoria Paulista reside em dar visibilidade às violações do direito à moradia e afirmar este direito, seja defendendo sua justiciabilidade frente ao entendimento, ainda muito frequente no sistema de justiça, de que se trata de norma programática, não passível de ser exigida perante os Tribunais; seja reafirmando-o como direito, em contraponto ao entendimento liberal de que se trata de um bem ou mercadoria a ser adquirido, mais do que um direito a ser cobrado do Estado.

Problematizar a atuação da instituição nesse campo implica pensar em dois elementos centrais: a primazia do direito de propriedade em relação aos direitos relacionados à posse, no interior do Judiciário, e os limites da própria judicialização dos direitos sociais.

\section{Direito à moradia e judicialização}

A proposição constitucional do direito à moradia instala a responsabilidade pública em seu cumprimento. Diante da violação desse direito, o Estado pode ser acionado ou contestado judicialmente e, nesse caso, em se tratando de populações vulneráveis ou sem recursos, a Defensoria Pública se apresenta como um ator importante, passível de ser acionado nos conflitos.

A atuação da Defensoria Paulista em relação ao direito à moradia ocorre em múltiplas frentes, como a interlocução com a gestão pública, a educação em direitos, e a judicialização das demandas, que se dá no questionamento ou cobrança do ente público no cumprimento de funções legalmente previstas, como processos de regularização fundiária com finalidade social, exigência de participação popular em processos de interesse da população, questionamento legal de condutas e ações públicas tidas como lesivas ao direito à moradia. Para os fins desse artigo tratar-se-á apenas da última forma de atuação.

Discutir o papel da DPESP a partir da chave analítica da judicialização dos direitos sociais implica pensar uma série de questões, que dizem respeito aos processos de judicialização da política de forma mais geral, e à judicialização do direito à moradia, de forma particular. Considerando-se os objetivos desse artigo, importa discutir quatro dessas questões, a saber: a questão sobre o papel do Judiciário na efetivação de direitos sociais e a exigibilidade desses direitos (o que se poderia chamar de questões teóricas) por um lado; e, por outro, as questões sobre a forma de tutela dos direitos sociais (individual ou coletiva) e as implicações sociopolíticas da realização efetiva do direito à moradia, que diz respeito ao enfrentamento da questão 
da redistribuição de recursos sociais e do estatuto da propriedade privada que não cumpre sua função social.

Estudiosos do tema apontam para o fato de que a judicialização dos direitos sociais envolve críticas de diversas ordens, as quais orientam, em grande parte, as decisões do Judiciário em relação aos litígios sobre os quais é chamado a intervir.

Uma das principais críticas presentes no debate diz respeito à questão da legitimidade do Judiciário em cobrar da gestão pública a concretização dos direitos sociais, o que seria contrário ao princípio da separação e equilíbrio entre os poderes, segundo o qual caberia ao Legislativo e ao Executivo a proposição e efetivação desses direitos, enquanto ao Judiciário caberia apenas fiscalizar sua efetivação, não sendo de sua competência determinar a execução de políticas públicas (TERRAZAS, 2010; CITTADINO, 2002).

Para os que defendem essa tese, a atuação do Judiciário para efetivação dos direitos sociais poderia, inclusive, gerar distorções, por interferir no campo de atuação dos outros poderes, e, ademais, pelo risco de desorganizar a administração, especialmente no que diz respeito aos impactos orçamentários não previstos que as decisões do Judiciário imporiam à administração pública.

A essa crítica soma-se outra, de igual importância, que questiona a própria justiciabilidade dos direitos sociais. Trata-se, nesse caso, da interpretação jurídica que afirma o caráter fundamental dos direitos sociais e sua aplicabilidade imediata, ou, em sentido contrário, que os interpreta enquanto norma programática, não dotados de eficácia imediata, mas normas que servem para orientar ações públicas de longo prazo, por meio de políticas públicas, e, nesse sentido, não passíveis de cobrança diante do Judiciário (SOUZA NETO, 2010).

Na tutela do direito à moradia, a crítica à atuação do Judiciário na cobrança de políticas públicas e a problematização teórica sobre a justiciabilidade dos direitos sociais orientam fortemente a decisão de juízes quando da negação dos direitos pleiteados. Diversos estudos têm apontado a frequência desses argumentos em decisões judiciais que negam direito à regularização ou permanência de moradores em áreas ocupadas, em prol de outros direitos que se sobrepõem, como o direito de propriedade ou o direito difuso do meio ambiente (VELOSO; PEIXOTO; FABER, 2017; MILANO, 2017; AVANCI, 2014; LOPES, 2014).

É possível tensionar tais argumentos quando se pensa o tratamento dado pelo Judiciário ao direito à moradia em contraste com o direito à saúde, constante do mesmo artigo constitucional referente aos direitos sociais fundamentais (art. $6^{\circ}$.) mas beneficiado mais frequentemente por decisões favoráveis quando cobrado judicialmente (FANTI, 2009; MELLO, 2017). Conforme aponta Mello,

[...] a proteção judicial do direito à moradia não está na linha de frente do quadro geral da tutela jurisdicional dos direitos sociais. No Brasil, o número 


\section{Direito à moradia e judicialização: atuação da Defensoria Pública Paulista}

e a qualidade das decisões judiciais envolvendo o direito à moradia são muito pouco significativos quando comparamos com a situação de garantia ampla e bastante arrojada do direito à saúde e mesmo do direito à educação (MELLO, 2017, p. 2073).

O contraste no tratamento desses dois direitos pelo Judiciário é objeto de crítica dos entrevistados da Defensoria Paulista, apontado como uma das dificuldades para a efetivação do direito à moradia:

Porque a grande dificuldade na moradia é o entendimento do Judiciário de que ele é um direito. Na saúde, por exemplo, é muito mais pacífico. Se você precisa de um tratamento, de um medicamento, o Judiciário entende que é saúde, que é direito universal, e dá uma decisão favorável para que o poder público promova o direito à saúde daquela pessoa. Na moradia ainda não tem esse entendimento pacífico. Ainda se entende a moradia como algo a ser conquistado. 'Eu trabalhei, eu comprei minha casa'. 'Eu trabalho, eu pago meu aluguel'", (Defensora Pública) ${ }^{12}$.

É válido considerar que o entendimento que toma a habitação como algo a ser conquistado pelo esforço individual mediado pela compra é amplamente difundido no tecido social, ultrapassando o Judiciário, pois mostra-se afeito à própria condição de mercadoria a que esse artigo é reduzido na lógica capitalista de produção da cidade, como mostram trabalhos como o de Maricato (2015).

Ademais, é importante lembrar que os direitos sociais à saúde e à moradia apresentam trajetórias diferentes no seu reconhecimento constitucional, desfrutando, o primeiro, de maior adensamento jurídico. Enquanto o direito à saúde consta entre os direitos sociais fundamentais desde a promulgação da Carta Magna em 1988 (BRASIL, 2017), o direito à moradia só alcançaria esse estatuto doze anos mais tarde, por meio da Emenda Constitucional (EC) n ${ }^{0}$. 26/2000, mostrando, assim, as dificuldades e disputas enfrentadas para seu reconhecimento legal.

Mas para além da questão propriamente formal e jurídica, torna-se necessário considerar um elemento ainda mais importante, que diz respeito aquilo que está em disputa quando se trata desses dois direitos sociais, e que põe em evidência, a um só tempo, o estatuto da propriedade privada, sempre que deixe de cumprir sua função social, e a questão da redistribuição da riqueza social. Esses dois elementos, levantados quando se trata do cumprimento do direito à moradia, apontam para a complexidade de sua efetivação em relação ao direito social à saúde.

$\overline{12}$ Entrevista concedida à autora em 26 de maio de 2017. 


\subsection{Direito à moradia e função social da propriedade}

Em um contexto de urbanização excludente e desigual, nos conflitos fundiários a efetivação do direito à moradia passa, muitas vezes, pelo reconhecimento legal de direitos relacionados à posse (ou o reconhecimento de formas irregulares de ocupação da terra urbana). Em contraponto coloca-se a propriedade titulada, no momento em que a judicialização tende, justamente, a cobrar a sua função social, alegando prevalência da posse quando a função social não está sendo cumprida. Assim, posse e propriedade titulada se colocam em polos opostos; tornam-se objeto de conflito no momento em que a regularização fundiária de uma área, ou a recusa dos ocupantes em deixá-la, são cobradas pelo não cumprimento da sua função social.

O Estatuto da Cidade prevê o reconhecimento da posse, desde que respeitados determinados critérios, como o tempo de permanência dos moradores no espaço ocupado e sua vinculação ao uso para fins de moradia, como já referido anteriormente $^{13}$. No entanto, mesmo no contexto dessa previsão legal, em caso de conflito entre posse e propriedade, na prática, as decisões judiciais ainda são frequentemente orientadas pela defesa da propriedade individual titulada, mesmo quando esta não cumpre sua função social, em detrimento do reconhecimento legal da posse (SAULE JR.; DI SARNO, 2013).

A função social da propriedade, também positivada na legislação nacional, cria condicionalidades ao direito de propriedade, ao afirmar que este não se exerce de maneira absoluta mas deve estar submetido ao bem coletivo e ao bem estar social. As controvérsias em torno dessa exigência colocam tal preceito no centro dos conflitos e disputas do direito à moradia. Analisando decisões judiciais em relação a esses litígios, diferentes estudiosos (LOPES, 2014; AVANCI, 2014) têm sido quase unânimes ${ }^{14} \mathrm{em}$ afirmar que a função social da propriedade ainda carece de reconhecimento por parte do Judiciário, para quem predomina o entendimento e a defesa da propriedade como bem individual e inalienável.

Da mesma forma, os profissionais do NHU também são enfáticos ao afirmarem a questão da função social da propriedade e seu devido reconhecimento pelo Judiciário como um dos principais desafios na judicialização do direito à moradia. Segundo relatam, esta afirmação está presente nas peças judiciais que orientam a defesa de moradores irregulares e nos espaços em que a instituição leva a debate público as pautas do direito à moradia, de que foi exemplo o I Seminário de Direito Urbanístico, promovido pela instituição em agosto de 2016,

\footnotetext{
${ }_{13}$ Artigos $9^{\circ}$. e 10 do Estatuto da Cidade (BRASIL, 2002).

${ }_{14} \mathrm{Um}$ dos poucos estudos que afirmam a aderência do Judiciário ao princípio da função social da propriedade é o de Colin Crowford (2017).
} 
e que dedicou duas sessões inteiras do encontro exclusivamente ao tratamento do tema ${ }^{15}$.

O instrumento da usucapião individual (aplicável a áreas privadas), que permite reconhecer legalmente a posse de um ocupante decorridos cinco anos de sua permanência no local sem oposição de outrem, é um dos instrumentos frequentemente acionados na cobrança do direito à moradia, e possui, segundo os defensores entrevistados, maior aderência do Judiciário. A presença antiga desse instrumento no direito brasileiro (constante já do Código Civil de 1916), somada à forma como a propriedade é nele entendida, são fatores possíveis para explicar a maior aceitação desse instrumento. Prevalece, nesse caso, uma visão individual de propriedade, em que se aceita que cada ocupante, individualmente, tenha direito à regularização da fração de terra ocupada, provocando efeitos sociais reduzidos numa estrutura fundiária excludente. Ainda assim, é válido lembrar as dificuldades enfrentadas pelos ocupantes até a titulação efetiva, em processos que podem durar décadas, atravessados por desistências ou até mesmo o falecimento de moradores ao longo do processo.

Mas é no uso do instrumento da usucapião coletiva, em casos de difícil identificação individual dos lotes, que se encontra a maior resistência por parte do Judiciário:

Usucapião coletiva tem resistência do Judiciário. Mesmo quando tem sentenças de procedência, são difíceis de executar na prática [...]. Em geral a gente faz para segurar a posse. Se tem um conflito e a gente não tem como fazer 200 ações individuais, por falta de tempo, a gente opta por uma coletiva para segurar a posse. Quando tem tempo, não tem ameaça à posse, e vê que é possível individualizar, a gente individualiza. O Judiciário tem menos resistência. Acho que quando um juiz vê uma área inteira que vai ser passada em benefício de uma comunidade, assusta. Quando ele vê que são casas individuais, acho que o impacto é menor [...] (Defensora Pública) ${ }^{16}$.

Muitas vezes a ação individual é buscada pela Defensoria como meio de potencializar as chances de sentenças positivas por parte do Judiciário, tido como órgão orientado, sobretudo, pela defesa dos direitos individuais ${ }^{17}$, mas na própria

\footnotetext{
${ }^{15}$ Foram elas: "Política urbana: o descumprimento da função social da propriedade como violação de direitos humanos fundamentais sociais" e "Os instrumentos indutores da função social da propriedade". Disponível em: <https://www.defensoria.sp.def.br/dpesp/repositorio/20/cartazes_eventos/08_ago_2016/15\%20e\% 2016_08_\%20l\%20Seminário\%20de\%20Direito\%20Urban\%C3\%ADstico.pdf>. Acessado em: 23 ab. 2018 ${ }^{16}$ Entrevista concedida à autora, em 26 de maio de 2017.

${ }^{17}$ Em estudo sobre a judicialização da saúde no município de São Paulo Fanti (2009, p. 85) também aponta que a via coletiva "mostra-se não apenas menos utilizada, como também revela um maior índice de julgamentos improcedentes por parte do Poder Judiciário".
} 
Defensoria Paulista se reconhece a tutela dos direitos coletivos como um desafio ainda a ser superado pela instituição. Vale lembrar que o reconhecimento das defensorias como órgãos legitimados para a propositura de Ações Civis Públicas, uma das formas de representação dos direitos coletivos, só foi reconhecida em 2015, vencendo muitas resistências dentro de outros órgãos do sistema de justiça ${ }^{18}$.

Assim, a forma de representação na defesa do direito à moradia, individual ou coletiva, apresenta-se como outro elemento que põe a judicialização dos direitos sociais em perspectiva crítica. Diferentes autores (CARVALHO, 2016; SOUZA NETO, 2010) apontam para o risco de excesso de judicialização dos direitos sociais por meio de demandas individuais, a chamada judicialização fragmentada, que comprometeria a distribuição igualitária de benefícios sociais, uma vez que os resultados dos litígios limitam-se aos indivíduos envolvidos no processo, tendo pouca eficácia social ${ }^{19}$.

\subsection{Direito à moradia e justiça distributiva}

Os desafios postos à judicialização do direito à moradia envolvem ainda um outro elemento, que diz respeito aos efeitos ou impactos sociais que sua real efetivação traria.

O tema é discutido de forma provocadora no estudo de Ferraz (2011), Harming the poor through social rights litigation: lessons from Brazil. O autor, ao contrastar processos de judicialização do direito à saúde e à moradia vai além da crítica ao suposto conservadorismo presente no Judiciário, ainda que o admita. $\mathrm{O}$ autor coloca a questão da redistribuição da riqueza no centro de sua análise sobre a judicialização dos direitos sociais.

Para Ferraz (2011, p.1666), a taxa de sucesso na litigância dos direitos à saúde está ligada, provavelmente, ao fato de que são baixos os efeitos na redistribuição da riqueza social, uma vez que pleiteada sobretudo de forma individual (e, portanto, com retornos também individuais), por aqueles que têm maior conhecimento e acesso ao sistema de justiça, isto é, as classes sociais mais privilegiadas. Contrariamente, a real efetivação do direito à moradia, mesmo que entendida como acesso a um "mínimo decente", implicaria significativa redistribuição de recursos na sociedade, uma vez que a dimensão da desigualdade no Brasil exigiria grande alocação orçamentária

\footnotetext{
${ }^{18}$ Em 2015 o Supremo Tribunal Federal (STF) julgou improcedente Ação Direta de Inconstitucionalidade (ADI) ajuizada pela Associação Nacional do Ministério Público (CONAMP) contra a Lei 11.448/2007 que inclui a Defensoria Pública como órgão legitimado para a tutela coletiva.

${ }^{19} \mathrm{Em}$ sentido contrário, que dá conta das polêmicas envolvendo o tema da judicialização, Fanti (2009) afirma que as demandas individuais no enforcement do direito à saúde têm resultados sociais positivos ao forçar o Executivo a implementar certas políticas e levar a seu conhecimento demandas sociais ignoradas.
} 
para as políticas relativas nesse campo, passando, inclusive, pela revisão das formas de tributação regressiva e a consequente transferência de recursos dos mais ricos para os mais pobres.

Diante disto, defende Ferraz (2011), as barreiras para a efetivação do direito social à moradia não se esgotam, ou não se limitam, ao Judiciário, mas se repõem na ausência de um consenso político e normativo dos diferentes atores sociais em torno da redistribuição da riqueza social, ou mesmo da percepção de que a desigualdade deva ser superada por meio dos direitos sociais, o que o autor nomeia como a ausência de um ethos igualitário na sociedade brasileira. Diante disso o autor questiona os alcances distributivos da interferência do Judiciário na efetivação dos direitos sociais: "Quando o ethos igualitário não está presente, é razoável esperar que os tribunais terão em algum momento o desejo ou o poder de realizar esta mudança radical através de ordens judiciais? (FERRAZ, 2011, p.1665, tradução nossa).

Assim, deve-se considerar que a efetivação do direito à moradia implica tocar em pelo menos duas questões muito sensíveis no atual quadro social, político e jurídico brasileiro. Por um lado, as injustiças da estrutura fundiária, e, dentro dela, as exigências postas ao cumprimento da função social da propriedade, o que entra em conflito com uma visão liberal da propriedade como bem individual a ser conquistado por empenho e mérito. Por outro, a exigência redistributiva de recursos sociais, capazes de fazer frente ao tamanho do déficit habitacional e de precariedade urbana em que vivem milhões de famílias brasileiras. Se a via judicial se torna, muitas vezes, ferramenta fundamental para a defesa e efetivação desses direitos, evidencia-se que seus alcances serão sempre limitados se tal defesa não envolver outros atores sociais e políticos, para a proposição e realização de políticas públicas e a cobrança que se deve fazer de sua efetivação, por meio da ação social e política de atores diversos, somados ao trabalho da Defensoria Pública.

\section{Conclusão}

A atuação da Defensoria Paulista nos conflitos fundiários urbanos possui o importante papel de afirmar, diante do Judiciário e da própria gestão pública, o direito à moradia como um direito social a ser garantido e promovido pelo Estado, indo além dos limites que se colocam na negação da sua justiciabilidade.

Os processos de judicialização, com pedidos de regularização fundiária, de permanência e regularização em lotes reivindicados por supostos proprietários titulares, ou mesmo pelo poder público, desempenha papel fundamental no tratamento do tema do direito à moradia, se não pela frequência de causas ganhas, por tensionar o formalismo do Judiciário no tratamento da questão, por meio da afirmação dos direitos relacionados à posse e da exigência de cumprimento da 
função social da propriedade. Segundo Souza Neto (2010, p. 518), o tratamento dos direitos sociais não se limita a mera questão de interpretação mas também, ou sobretudo, de decisão política. Daí a importância da Defensoria como ator que disputa os sentidos e o conteúdo concreto desses direitos.

Assim, no atual estágio do tratamento da questão da moradia, há que se considerar a importância da judicialização como meio de afirmar esse direito. No entanto, há que se reconhecer igualmente os limites desse processo, se este esvaziar o lugar da política como arena de debate e proposição de políticas públicas. Que o assunto chegue até o Judiciário já demonstra uma série de insuficiências no tratamento político do tema, quando não a própria violação de direitos, que por vezes alcança situações flagrantes de violações da dignidade humana.

É preciso, pois, recuperar e fortalecer o tratamento da questão da moradia em seu sentido político e em termos do que foi positivado pela Constituição Federal de 1988 (BRASIL, 2017). E, nesse sentido, certamente o trabalho ultrapassa a Defensoria Pública, sendo necessário levar em consideração os movimentos sociais e demais atores sociais e políticos capazes de afirmar e cobrar a efetivação desse direito.

O caso da Ocupação Povo Sem Medo, ocorrido no município de São Bernardo do Campo em 2017, se apresenta como caso fértil para pensar a importância dos movimentos sociais na cobrança de efetivação do direito à moradia. A ocupação, realizada pelo Movimento dos Trabalhadores Sem Teto (MTST) em terreno privado, ganhou grande repercussão, pelo número de famílias envolvidas e o grau de mobilização que alcançou. Após meses de mobilização os ocupantes conseguiram do governo estadual a cessão de terrenos para construção de moradias. Nesse caso foi o movimento social, não por meio da judicialização, mas por meio da mobilização e do embate político, e o consequente poder de negociação que estes geraram, o ator capaz de afirmar o direito à moradia das famílias e pressionar a gestão pública pelo seu reconhecimento. O que estava em jogo não era o direito de permanecer ou não no local ocupado, mas a afirmação, por meio da ocupação, de um direito a ser reconhecido e efetivado, podendo sê-lo em outro lugar, estratégia daqueles para quem somente a insurgência contra o que está estabelecido permite acessar a efetivação real do direito (COMARU, 2016; BARBOSA, 2014; HOLSTON, 2013).

Por fim, há que se considerar que a efetivação do direito à moradia exigiria alterações profundas na sociedade brasileira, passando obrigatoriamente pela redistribuição da riqueza social, o que ultrapassa certamente o papel do Judiciário. Isso não significa dizer que, diante do conflito judicializado, não se possa cobrar do poder Judiciário a consideração de questões como a função social da propriedade e os direitos relacionados à posse, necessárias à efetivação do direito à moradia. A Defensoria Paulista exerce importante papel nesse sentido, mas certamente os alcances do seu trabalho dependem do engajamento de outros atores sociais 
e políticos capazes de propor, implementar e fiscalizar a realização de políticas públicas urbanas e habitacionais.

\title{
RIGHT TO HOUSING AND JUDICIALIZATION: THE ROLE OF THE PUBLIC DEFENDER'S OFFICE
}

\begin{abstract}
This article aims to discuss the role of the Public Defender's Office of the State of São Paulo (DPESP) in urban land conflicts, through the question of the institution's role in fulfilling the social right to housing. In order to do so, the article focuses on the public defenders' discourses, through their interviews. The work's theoretical framework is the judicialization of social policies, detailing the dilemmas and limitations of judicialization in the field of right to housing. It concludes that the role of the Public Defender is to affirm the right to housing as a social right that should be enforced by the State, through the assertion of the intrinsic relationship between this right and the fulfilment of the social function of property.
\end{abstract}

KEYWORDS: Public Defender. Urban conflicts. Right to housing. Social function of property. Judicialization.

\section{DERECHO A LA VIVIENDA Y JUDICIALIZACIÓN: actuación de la Defensoría Pública Paulista}

RESUMEN: En este artículo se propone discutir la actuación de la Defensoría Pública del Estado de São Paulo (DPESP) en los conflictos agrarios urbanos, a partir de la cuestión sobre el papel que la institución viene desempeñando en el cumplimiento del derecho social a la vivienda. Para eso, se toma por objeto central los discursos de los profesionales actuantes en la institución, con foco en las acciones realizadas por el Núcleo Especializado de Vivienda y Urbanismo (NHU), obtenidas por medio de entrevistas y levantamiento documental. El texto se orienta por el referencial teórico de la judicialización de las políticas sociales, apuntando a los dilemas y límites de la judicialización en el campo de la vivienda. Concluye que el trabajo de la Defensoría Paulista ha sido, sobre todo, el de afirmar el derecho a la vivienda como derecho social a ser promovido por el Estado, lo que se da por la afirmación de la relación intrínseca entre ese derecho y el cumplimiento de la función social de la propiedad, además de los derechos relacionados con la posesión.

PALABRAS CLAVE: Defensoría Pública. Conflictos agrarios urbanos. Derecho a la vivienda. Función social de la propiedad. Judicialización. 


\section{REFERÊNCIAS}

AVANCI, Juliana Lemes. A atuação do Poder Judiciário paulista frente aos conflitos socioambientais urbanos na Região Metropolitana de São Paulo: uma análise a partir da jurisprudência do Tribunal de Justiça. 2014. 105f. Dissertação (Mestrado em Planejamento e Gestão do Território) - Universidade Federal do ABC, Santo André, 2014.

BARBOSA, BENEDITO ROBERTO. Protagonismo dos movimentos de moradia no centro de São Paulo: trajetória, lutas e influências nas políticas habitacionais. 2014. 140 f. Dissertação (Mestrado em Planejamento e Gestão do Território) - Universidade Federal do ABC, Santo André, 2014

BRASIL. Estatuto da Cidade: guia para implementação pelos municípios e cidadãos. Lei no. 10.257, de 10 de julho de 2001. Brasília, Câmara dos Deputados, 2002 (2a. edição).

BRASIL. Ministério Das Cidades. Conselho Das Cidades. Resolução Recomendada no. 87, de 8 de dezembro de 2009. Recomenda ao Ministério das Cidades instituir a Política Nacional de Prevenção e Mediação de Conflitos Fundiários Urbanos. Diário Oficial da União. Brasília: 25 de maio de 2010, seção 1 , no. 98 , p. 88.

BRASIL. Constituição da República Federativa do Brasil de 1988. Tribunal Regional do Trabalho da $2^{a}$ Região. Atualizada até a EC no 99, de 14/12/2017. Diário Oficial da União - DOU, 15 de dezembro de 2017. Disponível em: <http://www.trtsp.jus.br/legislacao/ constituicao-federal-emendas $>$. Acessado em 30 nov. 2018.

CARDOSO, Luciana Zaffalon Leme. Uma fenda na justiça: a Defensoria Pública e a construção de inovações democráticas. São Paulo: Hucitec, 2010.

CARDOSO, Adauto Lucio; ARAGÃO, Thêmis Amorim, JAENISCH, Samuel Thomas (orgs.). Vinte e dois anos de política habitacional no Brasil: da euforia à crise. Rio de Janeiro: Letra Capital: Observatório das Metrópoles, 2017.

CARVALHO, Sabrina Nasser de. Processos coletivos e políticas públicas: mecanismos para a garantia de uma prestação jurisdicional democrática. São Paulo: Editora Contracorrente, 2016.

COMARU, Francisco de Assis. Áreas centrais urbanas e movimentos de moradia: transgressão, confrontos e aprendizados. Revista Cidades, Presidente Prudente, vol. 13, no. 22 , p. 71-93, 2016.

CITTADINO, Gisele. Judicialização da política: constitucionalismo democrático e separação de poderes. In: VIANA, Luiz Werneck (org.) A democracia e os 3 poderes no Brasil. Belo Horizonte: Ed. da UFMG; Rio de Janeiro: IUPERJ/FAPERJ, 2002. 
CROWFORD, Colin. A função social da propriedade e o direito à cidade: teoria e prática atual. Texto para discussão, Brasília: Rio de Janeiro, IPEA, no. 2282, março de 2017.

FANTI, Fabíola. Políticas de saúde em juízo: um estudo sobre o município de São Paulo. 2009. 105f. Dissertação (Mestrado em Ciência Política) - Faculdade de Filosofia, Letras e Ciências Humanas da Universidade de São Paulo, São Paulo, 2009.

FERRAZ, Octavio Luiz Motta. Harming the poor through social rights litigation: lessons from Brazil. Texas Law Review, Austin, vol. 89, no. 2, p. 1643-1668, 2011. Disponível em: http://texaslawreview.org/wp-content/uploads/2015/08/Ferraz-89-TLR-1643.pdf. Acessado em: 11 abr. 2017.

FJP - FUNDAÇÃO JOÃO PINHEIRO. Déficit habitacional no Brasil 2015. Belo Horizonte: Diretoria de Estatística e Informações. FJP, 2018. 78 p. (Estatística \& Informações; n. 6)

HOLSTON, James. Cidadania insurgente: disjunções da democracia e modernidade no Brasil. São Paulo: Cia. das Letras, 2013.

LOPES, Roberta Castilho Andrade. A Construção do Direito à Moradia no Brasil: da Formação da Norma à Judicialização no Tribunal de Justiça do Estado de São Paulo. 2014. 227f. Tese (Doutorado em Arquitetura e Urbanismo) - Faculdade de Arquitetura e Urbanismo da Universidade de São Paulo. São Paulo, 2014.

MARICATO, Ermínia. Para entender a crise urbana. São Paulo: Expressão Popular, 2015 MELLO, Cláudio Ari. Direito à moradia e conciliação judicial de conflitos coletivos possessórios: a experiência de Porto Alegre. Revista de Direito da Cidade, Rio de Janeiro, vol. 09, no 4, p. 2072-2098, 2017

MILANO, Giovanna Bonilha. Conflitos fundiários urbanos no poder judiciário: estratégias discursivas no fundamento das decisões. Revista de Direito da Cidade, Rio de Janeiro, vol. 09, no 4, pp. 2047-2071, 2017.

MUNIZ, Cibele Cristina Baldassa. Dos direitos sociais e sua defesa pela Defensoria. In: HADDAD, Eneida G. de Macedo. A Defensoria Pública do Estado de São Paulo: por um acesso democrático à justiça. São Paulo: Letras Jurídicas, 2011.

NASSAR, Paulo André Silva. Judicialização do direito à moradia e transformação social: análise das ações civis públicas da Defensoria Pública do Estado de São Paulo. 2011. 134 f. Dissertação (Mestrado em Direito e Desenvolvimento) - Escola de Direito de São Paulo da Fundação Getúlio Vargas, 2011.

ROLNIK, Raquel. Guerra dos lugares: a colonização da terra e da moradia na era das finanças. São Paulo: Boitempo, 2015. 
SAULE JÚNIOR, Nelson; DI SARNO, Daniela Campos Liborio (Coord.). Soluções alternativas para fundiários urbanos. Brasília: Ministério da Justiça, Secretaria de Reforma do Judiciário, 2013.

SILVA, Eliane Alves da e TEIXEIRA, Alessandra. Conflitos fundiários urbanos e sistema de justiça: judicialização da política ou politização da justiça? Mediações, Londrina, v. 21, n. 1, p. 124-144, 2016.

SOUZA NETO, Cláudio Pereira de. A justiciabilidade dos direitos sociais: críticas e parâmetros. In: SOUZA NETO, Cláudio Pereira de, e SARMENTO, Daniel. (coord.) Direitos sociais: fundamentos, judicialização e direitos sociais em espécie. Rio de Janeiro: Lumen Juris, 2010.

TERRAZAS, Fernanda Vargas. O Poder Judiciário como voz institucional dos pobres: o caso das demandas judiciais de medicamentos. Revista de Direito Administrativo, Rio de Janeiro, v. 253, p. 79-115, 2010. Disponível em: <http://bibliotecadigital.fgv.br/ojs/index. php/rda/article/view/8047>. Acessado em: 11 jul. 2018.

VELOSO, Luiza Lins; PEIXOTO, Marina Costa Craveiro e FABER, Rafael de Paula Eduardo. Propriedade e moradia à luz da função social: análise de julgados do judiciário paulista nas ações de reintegração de posse. Cadernos da Defensoria Pública do Estado de São Paulo. São Paulo, n.5, p. 8, 2017. [Litigância Estratégica].

Recebido em 14/08/2018.

Aprovado em 14/10/2018. 